\title{
Liability for delays in diagnosis - Waiting for trouble?
}

\author{
Thomas R Todd MD¹, Paul C Adams MD², Editor-in-Chief
}

$D_{c}^{r}$ Thomas R Todd is a Senior Medical Officer of the Canadian Medical Protective Association (CMPA). The CMPA was founded in 1901 and incorporated by the Act of Parliament in 1913. It is funded and operated on a not-forprofit basis for physicians, by physicians. Its membership of more than 71,000 comprises approximately $95 \%$ of the doctors licensed to practise in Canada.

PA: Most gastroenterologists in Canada face waiting time crisis for clinic assessments and endoscopy. Colonoscopy has become a recognized screening tool for colon cancer and yet the waiting times for colonoscopies - even with symptoms - can be measured in years in some areas. The Canadian Association of Gastroenterology has documented waiting time problems across Canada (1).

In my department, some gastroenterologists receive 15 to 20 requests for consultation per day. Let us look at a hypothetical scenario from the perspective of liability.

A 50-year-old man presents to his family physician with rectal bleeding. The problem has stopped and a rectal examination is normal.

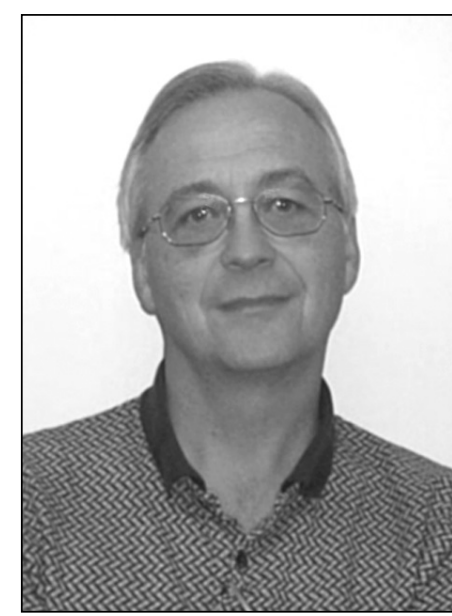

Dr Thomas $R$ Todd is a Senior Medical Officer of the Canadian Medical Protective Association for rectal bleeding but it seems easier in many places to get a barium enema long before a colonoscopy. Is this a good defensive strategy for family physicians?

TT: Anything that would facilitate early and clinically appropriate triage would be beneficial.

PA: Are hospitals under any obligation to provide a standard of care for providing access to endoscopic facilities?

TT: Hospitals and health authorities should be informed by the physician when the resources do not permit recommended wait times to be realized. The courts have held that hospitals owe an independent duty of care to patients, and have been held liable for breaches of that duty.

PA: We have just seen an announcement from Ontario Cancer Care encouraging large numbers of patients to have fecal occult blood testing. This will likely result in a large number of new referrals for colonoscopy and sufficient facilities are currently lacking.

TT: A strategy to address excessive wait times such as noted above would become even more important.

PA: In Britain, they legislated that patients A referral to several local gastroenterologists is attempted. The first gastroenterologist says he is no longer taking new referrals. The second gastroenterologist arranges an appointment for the patient to be seen in the clinic in nine months - the patient waits. Colonoscopy six months after the clinic appointment reveals a colon carcinoma with metastases to the liver. The patient asks why the system cannot allow for proper diagnosis and treatment.

TT: This is a legitimate question. Wait time issues could have been discussed with the patient at the outset by the family doctor and by the second gastroenterologist at the time of consultation. At the time of referral acceptance, the consultant could have informed the referring physician that the wait time for consultation was excessive for a case of rectal bleeding particularly if carcinoma is a possibility. A referral elsewhere could have been suggested or if unavailable, the consultant's office could ask the referring physician to inform the patient of the wait time concern. At the time of consultation the patient could have been informed by the gastroenterologist of the potential adverse events related to a further wait time of six months for the procedure. Under these circumstances the gastroenterologist might have had a discussion with the patient regarding adjunctive investigations before colonoscopy that would provide either reassurance or alter priority. All this would be documented in the clinical record.

PA: Most gastroenterologists would recommend colonoscopy with cancer-related symptoms must be seen within three weeks. All patients seemed to have a cancer-related symptom. This problem occurs with attempts at triage or urgent care clinics.

TT: In retrospect, many symptoms can be interpreted as cancer-related. This simply reinforces that physicians should advise patients when their wait times exceed the recommended benchmark. Patients should be advised of the potential adverse implications and the physician should discuss any alternatives, including the option of a referral elsewhere, either locally, provincially, nationally or to the United States.

PA: We have seen patients attempt legal action against family physicians and gastroenterologists for inability to provide appropriate care. Can this be redirected at hospitals that have not provided the facilities?

TT: If the failure to meet recommended wait times is due to a lack of resources, this should be identified to the health authority or institution. Should a subsequent adverse event occur, liability for the physician may be mitigated to some degree. However, if the physician was aware of the problem and cannot demonstrate that he/she brought the concern to the attention of the hospital authorities, they could be at risk for sharing the liability.

PA: Many gastroenterologists see an introduction of technical fees for endoscopy as a solution to this problem, which would

${ }^{1}$ Canadian Medical Protective Association, Ottawa; ${ }^{2}$ University Hospital, London, Ontario

Correspondence: Dr Thomas R Todd, Canadian Medical Protective Association, 875 Carling Avenue, Ottawa, Ontario K1S 5P1.

Telephone 1-800-267-6522

Received for publication February 8, 2007. Accepted February 8, 2007 
allow them to set up their own ambulatory endoscopy facilities. This would likely reduce waiting times although it may introduce new issues, including legal problems.

TT: CMPA members who establish private clinics should be aware of the prerequisites for the association's assistance to the clinic or facility and its employees were they to encounter medico-legal difficulty. Physicians need to be aware of the applicable licensing and billing requirements in place in their jurisdiction.

PA: Many specialists have commented that the current government plan to reduce waiting times in five key areas increased waiting times for other procedures, including colonoscopy.

TT: The Association is aware of this concern in the medical community and readers are referred to the recent Canadian Medical Association publication entitled "Specialty care online consultation - overview of access and wait time results" (2).

PA: A growing number of patients ask to go to the United States for rapid access to treatment. However, for reimbursement, the treatment needs preapproval and this rarely seems possible. Who decides what is an appropriate wait time?

TT: Governments have defined the wait time benchmarks currently accepted for the five priority areas with the assistance of the medical community. These are expected to result in rapid approval for patients to seek care elsewhere, even in the United States, provided care proves to be unavailable in Canada within the wait time. As benchmarks are developed for other clinical areas, we expect the same principle to apply. In the meantime, physicians will need to use their best judgment based on experience and their interpretation of the literature. When in the physician's opinion the wait time is excessive, it is appropriate to advocate for the patient and assist in referral elsewhere or to the United States if necessary. Physicians should be aware of applicable requirements for out-of-province/territory referral, as a number of provinces and territories have established procedures which must be met in such circumstances for the treatment to be publicly funded, especially in the case of out-of-country referral.

\section{REFERENCES}

1. Paterson WG, Depew WT, Pare P, et al. Canadian consensus on medically acceptable wait times for digestive health care. Can J Gastroenterol 2006;20:411-23.

2. Canadian Medical Association. Wait Time Efforts Leaving Some Patients Behind. <www.cma.ca/index.cfm/ci_id/51422/la_id/1.htm> (Version current at May 30, 2007). 


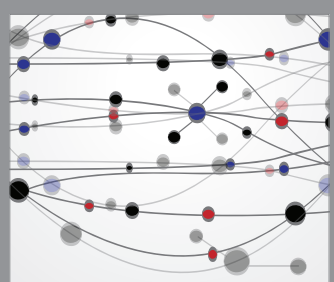

The Scientific World Journal
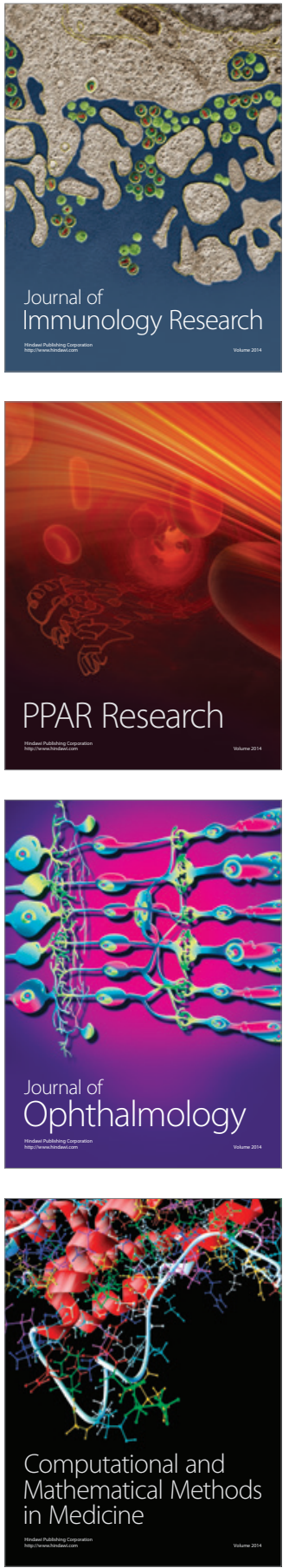

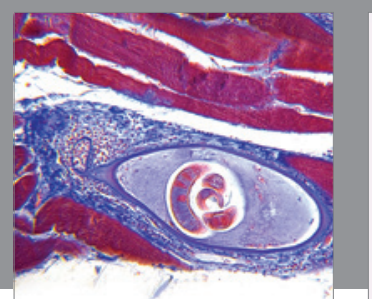

Gastroenterology Research and Practice

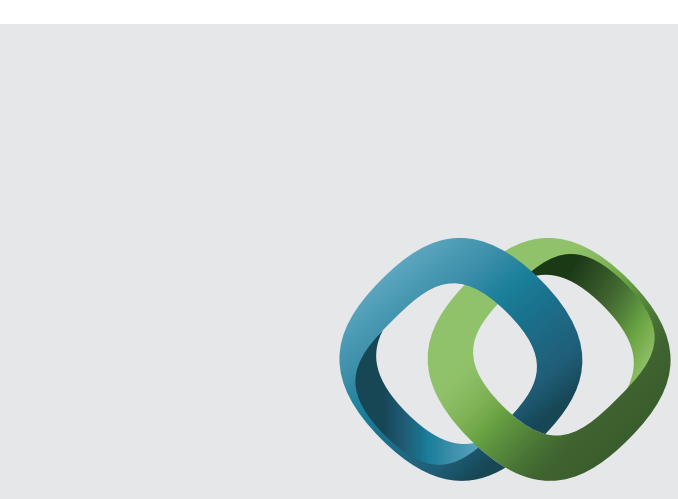

\section{Hindawi}

Submit your manuscripts at

http://www.hindawi.com
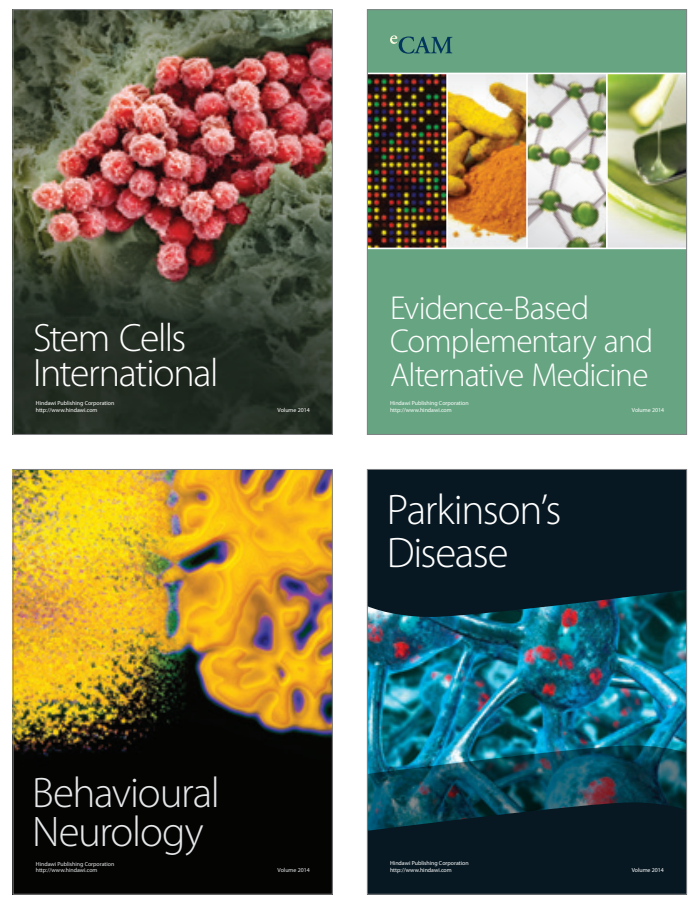
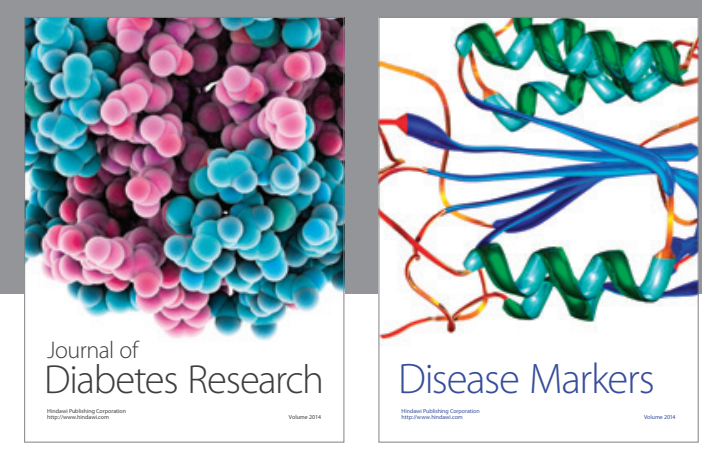

Disease Markers
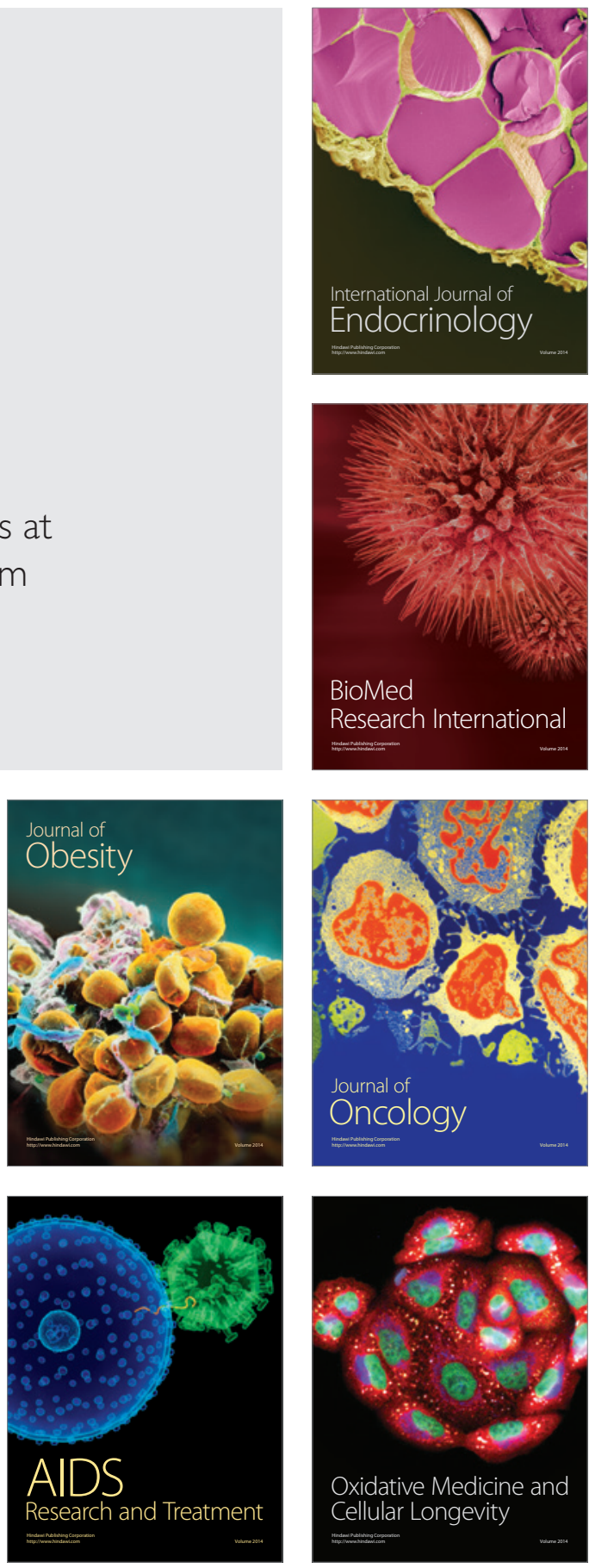